\title{
VOZ Y REPRESENTACIÓN DE LA INFANCIA EN EL PROYECTO LITERARIO DE LYGIA BOJUNGA
}

\section{VOZ E REPRESENTAÇÃO DA INFÂNCIA NO PROJETO LITERÁRIO DE LYGIA BOJUNGA}

\author{
María de Los Ángeles Lugo Colina ${ }^{1}$
}

\begin{abstract}
Resumen: En este trabajo se estudiará cómo la narrativa de Lygia Bojunga emerge en el escenario de la literatura para dar voz y representar el discurso de la infancia. La representación aparecerá estudiada desde dos enfoques; el de -representar- como -hablar en nombre de- y representar-, desde una perspectiva performática, entendiendo que en la obra de esta autora la forma narrativa se articula con la forma teatral para, a partir de un discurso metaliterario, estimular el surgimiento de una conciencia crítica y promover la ruptura de la subalternidad a la cual la infancia se encuentra sujeta. Para este trabajo se implementó una metodología de corte bibliográfico, haciendo una revisión de diez libros de la autora, publicados entre 1972 y 1988, siendo consideradas las ideas de Djamila Ribeiro, Gayitri Spivak, Antonio Cándido, Paulo Freire, Regina Zilberman, Maria Teresa Anduetto, entre otros autores para dar sustento teórico a los planteamientos expresados. ${ }^{2}$
\end{abstract}

Palabras clave: Literatura, voz, representación, subalternidad, emancipación.

Resumo: Este trabalho estudará como a narrativa de Lygia Bojunga emerge no palco da literatura para dar voz e representar o discurso da infância. A representação será estudada a partir de duas abordagens: o de -representar- como -falar em nome de- e -representar-, a partir de uma perspectiva performática, compreendendo que na obra dessa autora a forma narrativa se articula com a forma teatral para, a partir de um discurso metaliterário, estimular a emergência de uma consciência crítica e promover a ruptura da subalternidade à qual a infância está sujeita. Para este trabalho, foi implementada uma metodologia de recorte bibliográfico, fazendo-se uma revisão de dez livros da autora, publicados entre 1972 e 1988, sendo consideradas as ideias de Djamila Ribeiro, Gayitri Spivak, Antonio Cándido, Paulo Freire, Regina Zilberman, Maria Teresa Anduetto, entre outros autores para dar suporte teórico às abordagens expressadas.

Palavras-chave: Literatura, voz, representação, subalternidade, emancipação.

\footnotetext{
1 Es Licenciada en Educación mención Lengua y Literatura por la Universidad Nacional Experimental "Francisco de Miranda", Venezuela. Actualmente es estudiante de la Maestría en Letras: Enseñanza de la Lengua y la Literatura en la Universidad Federal de Tocantins, campus Araguaína, Brasil. E-mail: marialugo1989@gmail.com http://lattes.cnpq.br/1882497446605006

${ }^{2}$ Este trabajo fue producido en el marco de las disciplinas Mujeres Formadoras de Lectores, y Literatura: entre la lucha por la circulación y el veto, las cuáles fueron impartidas por la Doctora Ana Crelia Dias, profesora titular de la de la UFRJ, en la UFT durante los meses abril - junio y septiembre del 2019.
} 
"Los libros leídos son moradas emprestadas".

Michelle Petit

\section{Consideraciones iniciales}

Hablar de literatura infantil y juvenil en Brasil implica hacer mención obligatoria del nombre "Lygia Bojunga" (1932), autora que cuenta con 23 libros publicados hasta la fecha y que ha alcanzado renombre a nivel internacional ${ }^{3}$, pero cuya obra paradójicamente no es conocida por muchos brasileros; los más privilegiados quizás hayan leído El bolso Amarillo durante su educación primaria, otros quizás pudieron leer alguna obra de la autora durante su formación universitaria en Letras o Pedagogía, pero otros, infelizmente la mayoría, no han tenido acceso, ni a esta, ni a muchas otras obras de la literatura universal.

Esto quizás se deba a que el acto de leer es entendido por muchas personas como un privilegio, una actividad ligada al ocio y relacionada con la burguesía; y en cierta forma esta idea no está equivocada, puesto que las clases menos privilegiadas de la sociedad difícilmente tienen acceso a los libros. Sin embargo, no se trata de un privilegio, sino de un derecho indispensable", como lo es "el derecho a la creencia, a la opinión, al ocio y, por qué no, al arte y a la literatura". (CÁNDIDO, 2014, p. 174).

Ésta idea ha sido defendida por Antonio Cándido en su texto El derecho a la lectura (2014), donde se explica que no se trata de un ámbito superfluo ni gratuito, sino que la literatura tiene funciones claras dentro de la sociedad, a saber: "1, ella es una construcción de objetos autónomos con estructura y significado; 2, ella es una forma de expresión, esto es, manifiesta emociones y visión de mundo de los individuos y de los grupos; 3 , ella es una forma de conocimiento..." (CÁNDIDO, 2014 p. 176).

Considerando esta tercera función, podría explicarse el hecho de que la literatura infantil y juvenil con frecuencia sea relacionada al ámbito de lo educativo, lo ético y lo moralizante, y que deba adoptar estas perspectivas para "tornar patente su utilidad" 5 . Se verá que éste carácter utilitario concedido a la literatura infantil y juvenil surge para complementar la función que también se le asignó a la infancia a partir de la modernidad, la de "ser objeto de

\footnotetext{
${ }^{3}$ La obra de esta autora ha sido traducida a más de 12 idiomas; en 1980 fue galardonada con el Premio Hans Christian Andersen y en el 2004 el Premio sueco Astrid Lindgren.

${ }^{4}$ Antonio Cándido desarrolló esta idea a partir del concepto de "bienes incomprensibles" planteado por Louis Joseph Lebret.

${ }^{5}$ Esta idea ha sido descrita como detalle por Regina Zilbernan y Marisa Lajolo en el libro Literatura infantil brasileira: história e histórias (1989).
} 
atención e interés de los adultos" 6 .

Según estas autoras, "atributos como la fragilidad, la desprotección y la dependencia" serán considerados como característicos de esta fase etaria; pero es sabido que no se trata sólo de aspectos que hacen que la infancia sea calificada de forma negativa, sino que también son realidades y desafíos que los niños y jóvenes del mundo entero están obligados a afrontar; la infancia será vista como un grupo incompleto, que "adolece" de madurez y convicción, los cuáles al depender afectiva y económicamente de los adultos, se encuentran en una situación de subordinación, y como podría deducirse, "las opresiones que recaen sobre la infancia, además de presuponer modalidades de desigualdad en la relación entre niños y adultos, exige concebir a éste grupo social como subalterno. (FIGUEROA, 2016, p. 84).

Quizás para los padres amorosos, los maestros abnegados, o los adultos idealistas, la idea de la infancia como un sujeto subalterno ${ }^{7}$ pueda parecer un tanto extremista, pero es precisamente éste el aspecto que aquí será estudiado, pues como se verá, en la narrativa de Lygia Bojunga, tanto los niños y adolescentes provenientes de familias de clase media y alta, como los niños en situación de pobreza y orfandad, experimentan situaciones adversas que los colocan en el plano de la subalternidad.

Tomando en consideración el hecho de que la primacía del pensamiento adultocéntrico necesariamente implica el apagamiento de la voz de la infancia, nuestra hipotesis apunta a señalar que en la obra de Lygia Bojunga se ofrece al lector una alternativa; las historias presentadas tienen como protagonistas a niños y jóvenes, y dichos personajes al apropiarse de herramientas como la escritura y la representación teatral, logran subvertir el orden y romper con las imposiciones que limitan a la infancia, consiguiendo así su emancipación, y como señala Regina Zilberman, no sólo la de la infancia, sino la del ser humano, propiciando "la mudanza de las circunstancias que producen tales mecanismos de dominación. (ZILBERMAN, 2003, p. 221)

Se verá que es precisamente en el espacio de la literatura infantil y juvenil donde la infancia podrá adquirir voz y ser re-presentada, encontrando un discurso que busca entender y explicar el mundo desde este modo de visión, o al menos intenta trasladarse a este lugar de habla.

\footnotetext{
${ }^{6}$ (ZILBERMAN, LAJOLO, 1989, p. 17)

${ }^{7}$ El término subalterno es usado para referirse en las ciencias sociales a sectores marginalizados y a las clases inferiores de las sociedades; el uso de este término aparece implementado por primera vez por Antonio Gramsci en sus Cuadernos de la Cárcel (1975).
} 


\section{El lugar de habla de la infancia en la literatura infantil y juvenil}

Pero ¿cuál es lugar de habla de la infancia? y ¿cómo un lector o un escritor adulto puede apropiarse de este discurso o acaso acercarse a entenderlo? Para dar respuesta a estas preguntas será necesario aceptar, que si bien todos fuimos niños alguna $v e z^{8}$, es un hecho evidente que ya no lo somos, y que cada vez nos alejamos más de este momento; queriendo esto decir, que no por el hecho de ser un adulto significa que se tiene propiedad para hablar en nombre de los niños y jóvenes; entonces cabría preguntarse ¿quién puede hablar sobre la infancia? ¿Los psicólogos? ¿Los padres?, ¿Los maestros?

El concepto "lugar de habla" aparece de forma oportuna para entender un asunto que tiene mucho que ver con la localización social, y se refiere al punto de vista desde donde se emite alguna reflexión; la autora Djamila Ribeiro explica que "todo mundo tiene lugar de habla" (RIBEIRO, 2017, p. 82), la cuestión sería entonces, al leer, y mucho más, al escribir, preguntarse desde dónde se está enunciado ese discurso y si esas ideas verdaderamente representan a esa comunidad por la cual se pretende hablar, o si por el contrario apagan su voz.

Esta idea podría articularse con los planteamientos de Gayitri Spivac, quien en su libro ¿Puede hablar el subalterno? explica que los intelectuales al intentar explicar un fenómeno de la subalternidad, se apropian de él, incurriendo muchas veces en el error de asumir al otro por asimilación, es decir, ser intelectual y -hablar en nombre de- creyendo que se es "transparente", cuando en realidad los pensamientos expresados están atravesados por la perspectiva occidental. Si Spivac reflexiona al respecto de "cómo es representado en el discurso occidental el sujeto del tercer mundo" (SPIVAC, 2003, p. 301) aquí buscamos reflexionar precisamente en torno a cómo es representada la voz de la infancia en la sociedad, y específicamente estudiar cómo en la obra de Lygia Bojunga se plantea una denuncia de los mecanismos mediante los cuales se tiende a la subalternización de la infancia.

En este trabajo nos interesa destacar cómo la autora muestra en su proyecto narrativo una postura definida", la cual se encuentra en consonancia con la idea de que "la intelectual femenina tiene una tarea circunscrita que no debe rechazar con una rúbrica" (SPIVAK, 2003, p. 362). Consideramos que Lygia Bojunga asume esta responsabilidad, permitiendo afirmar que, si tal señala Paulo Freire: "los libros en verdad reflejan el enfrentamiento de sus autores con el mundo" (FREIRE, 1975, p.13), el discurso presentado permite hablar de una autora y

\footnotetext{
${ }^{8}$ Sólo personajes de la ficción como Benjamin Buttom, quien nació siendo adulto, o en todo caso Peter Pan, quien fue niño para siempre constituirían excepciones.

${ }^{9}$ La cual como se verá más adelante ha sido objeto de críticas y acusaciones.
} 


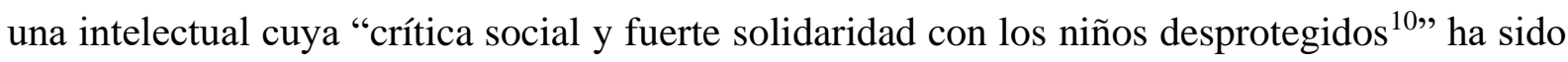
reconocido como un rasgo característico de su obra, demostrado así su compromiso para con la infancia.

\section{El sujeto subalterno en la obra de Lygia Bojunga, ¿una denuncia?}

Veamos algunos argumentos abordados en la obra de la autora, lo cuales permiten ejemplificar esta idea; En Los amigos, Cara de palo ha sido "perdido" voluntariamente por su familia, es decir, abandonado, y además, todos los personajes de esta obra viven en la calle y comen de la basura; Angélica es un cigüeña excluida del seno familiar por no querer ser parte de una mentira; Raquel, de El Bolso Amarillo es objeto de burla por querer ser escritora; Alexandre de La casa de la Madrina es un niño incentivado por su propia familia a dejar los estudios para asumir la responsabilidad de trabajar; María en La Cuerda Floja después de quedar huérfana va a vivir con su abuela, quien cree que puede comprar a las personas; Víctor, de El Sofá estampado es explotado laboralmente y llevado al límite de perder su dignidad. En Adiós se cuentan varias historias: La de Rebeca y su hermano, que son abandonados por su madre, dejándolos solos con un padre alcohólico, la de Tuca en El bistec y las cotufas, quien vive en una favela en medio de la pobreza, tiene que trabajar y su madre es una alcohólica también. Rafaela en Nosotros tres es testigo del asesinato de su amigo Davi; y el niño protagonista de Mi amigo Pintor intenta entender lo que es el suicidio a través de la experiencia de la muerte de su mejor amigo.

En la obra de Lygia Bojunga estos temas mencionados son presentados al lector sin ser velados o disimulados, aunque estos irán apareciendo de forma progresiva en la obra de la autora, aumentando su intensidad y profundidad dramática con el trascurrir de los años, puesto que como han coincidido en señalar investigadoras como Laura Sandroni y Ana Crélia Dias, la obra de Lygia Bojunga amadurece junto con el lector; inclusive, esta "evolución" ha sido explicada por Vera María Tietzmann Silva, quien usando las propias metáforas implementadas por Lygia Bojunga ha señalado que en la obra de la autora es posible observar una fase luminosa y una fase cenicienta, a saber:

En la fase luminosa, se privilegia el lado mágico de la vida. La casa de la madrina de Alexandre, la bolsa de Raquel y sus contenidos, el caballo Ah son ejemplos de ello. En la fase cenicienta al contrario, prevalece el lado trágico, como se ve en el abandono de la madre, en el suicidio del amigo el pintor. En la fase luminosa, la iniciación es para la vida, para el amor, la sexualidad y la independencia, (como en los cuentos de hadas). En la fase cenicienta, la iniciación es para el enfrentamiento del dolor, del

\footnotetext{
${ }^{10}$ Extraído del acta del fallo del Jurado del Premio Astrid Lingrend 2004.
} 
sufrimiento y de la muerte. La primera se puede tomar como la visión de la inocencia y la otra sería la visión de la experiencia. (TIETZMANN, 1995, s/p)

Cabría preguntarse si temas tales como la pobreza, la envidia, la soledad, el abandono, la muerte o el asesinato son temas aptos para la infancia. La respuesta es sí, estos argumentos abordados en la obra de la autora son temas que pueden y deben ser leídos por niños y jóvenes, claro está, con el tratamiento adecuado. Valdría la pena destacar, que a excepción de Los amigos, las creaciones de Lygia Bojunga no son únicamente "literatura infantil", sino que son libros que los niños y jóvenes también pueden leer. Al respecto de este hecho Lygia Bojunga ha dicho en una entrevista:

Me encanta cuando los niños se me acercan y me hablan sobre algo que escribí, cuando discuten conmigo sus ideas de un libro. Me encanta cuando lo que escribo logra llegar a ellos. Pero el "estigma" de autora para niños, aparta de mis libros a otros lectores que podrían conocerlos. Por favor, no quiero que digan que yo escribo para niños, pues entonces los grandes no me van a leer. ${ }^{11}$

Los libros de Lygia Bojunga se adecúan a la sensibilidad de la infancia, pero no por eso dejan de entretener, deleitar y conmover también a un lector adulto. Si bien en la obra de la autora es posible observar ese tipo de escritura "mas amorosa, mas implicada con el otro" (SILVA, MELO, 2015, p3), ese factor no equivale a que se trate de una literatura fácil o un discurso que infantiliza al lector, inclusive aunque el lenguaje implementado por la autora sea coloquial, tal como ha planteado Ana María Machado en el prólogo a La Casa de la Madrina: "escribir igualito a lo que la gente piensa puede parecer fácil, pero es una de las cosas más difíciles que existen".

Sin embargo "no hay reseña que pueda explicar la experiencia" 12 de la lectura infantil y juvenil, quedará en cada lector acercarse a esta literatura, la cual al colocar la densidad dramática en la perspectiva de la infancia logra conmover y producir una experiencia estética tanto en lectores experientes como a lectores iniciantes; pero para llegar a esta comprensión será necesario entender que la literatura infantil y juvenil es un género que posee criterios literarios tan válidos como el resto de la literatura, y que como señala María Teresa Anduetto en su libro Por una literatura sin adjetivos, "no existen temas de dominio exclusivo del mundo de los adultos, existen formas que son consideradas de su pertenecimiento" y que como ya ha

\footnotetext{
${ }^{11}$ Entrevista concedida a Antonio Orlando Rodríguez en 1991.

12 (SILVA, MELO, 2015, p. 10)
} 
sido señalado ${ }^{13}$, hacen que la literatura infantil y juvenil sea relegada a "lo funcional y a lo utilitario" $" 14$.

Podría decirse que si la literatura tiene alguna funcionalidad esa será la de "dar forma a los sentimientos y a la visión de mundo", pues ella "nos organiza, nos libera del caos y por tanto nos humaniza". (CÁNDIDO, 2014, p.186); es así que en el contexto de la narrativa de Lygia Bojunga se podría hablar de una literatura que "humaniza" a sus personajes, puesto que son presentados al lector "niños y animales en la experiencia del dolor de existir en un ambiente opresor" (DIAS, 2019), pero que a través de herramientas como la escritura y la representación teatral, pasan a convertirse en verdaderos sujetos, portadores de una voz propia.

\section{La escritura como herramienta de liberación}

Según ha señalado Lygia Bojunga, para ella la escritura ha sido libertadora, hecho que quizás motive la inclinación de la autora a compartir esta experiencia con sus lectores, trasladando este hecho al plano de la ficción; en Libro, un encuentro, la autora va a explicar que el cuento El trueque y la tarea en cierta forma es autobiográfico, pues refleja muchas de sus experiencias en torno a la escritura: "Un día, me dio por transformar cosas pequeñas; transformaba un dolor en coma; convertía un alivio en signo de exclamación; transformaba una esperanza en interrogación. Me gustó. Me sentí medio hechicera”. (BOJUNGA, 1984, p.32)

En el discurso narrativo expuesto por Lygia Bojunga se presenta al lector la práctica de la escritura sea un acto liberador. Los personajes con frecuencia hacen uso de las cartas como una forma de expresión, encontrando en la página en blanco un lugar para expresare; y aunque la mayoría de las veces la escritura sea un acto privado o inclusive estas cartas no tengan un interlocutor real ${ }^{15}$, personajes como Raquel, de El Bolso Amarillo, Rebeca de Adiós, o personajes innominados como la escritora de El trueque y la tarea, o el protagonista de $M i$ amigo Pintor, usarán las cartas como una forma de entender el mundo, problematizar su realidad, reflexionar, o simplemente ejercer la escritura como una actividad catártica.

También otros personajes en la obra de la autora emplearán la escritura como medio para expresarse, tal es el caso de Angélica quien "sabía música, sabía leer y escribir, hasta poesía sabía hacer"; pero además de los poemas ella también pasa a escribir teatro gracias la "idea"

\footnotetext{
${ }^{13}$ Regina Zilberman y Marisa Lajolo.

14 (ANDUETTO, 2009, p. 61).

15 Aunque como bien dice el dicho popular "la ambición secreta de quien escribe es ser leído".
} 
que le fue dada por su compañero Puerto ${ }^{16}$. Se hará notorio que el uso de la representación teatral ${ }^{17}$ adquiere una importancia clave, pues va a permitir a los personajes dar forma a su mundo, organizarlo para sí mismos y para los otros.

\section{La representación teatral en el proyecto literario de Lygia Bojunga.}

La novela Angélica es la obra de la autora donde mejor puede ser observado el teatro como forma de emancipación; en ella los personajes además de obtener una forma de sustento, conseguirán un espacio para expresarse, para librarse de sus inseguridades y miedos. Se hace llamativo que sea precisamente el capítulo titulado "La representación" el que vaya a ser decisivo para el auto-conocimiento y la auto-aceptación de cada uno de los personajes; dicha representación fue más un ensayo abierto que una primera función, pues dejó ver a los espectadores una serie de fallas y desperfectos, que sin embargo pudieron ser solventados gracias a la creatividad de sus personajes, y dejaron claro que en la vida así como en teatro "la función debe continuar".

También en la novela Los Amigos es gracias a un espectáculo que los personajes conseguirán una forma de sustento; estos quienes se reconocen como artistas, precisamente en el circo encontrarán el espacio perfecto para desarrollar su vocación. En otra obra, La Casa de la Madrina, Alexandre y el Pavón también usaran un "show" como una forma para generar dinero, y esto es lo que le permitirá a los protagonistas alejarse de ese ambiente de pobreza y explotación en el cual se encontraban inmersos, y seguir su camino hacia la casa de la madrina, es decir, hacia su propia utopía.

En La Cuerda floja María y sus padres son equilibristas, trabajan en un circo y cada día deben representar un número, pero es precisamente "equilibrando" que estos personajes pierden su vida, dejando huérfana a la protagonista. Por otra parte en El sofá estampado Víctor, el Armadillo debe representar para la televisión diferentes papeles, con el objetivo de aparecer en la pantalla y así conseguir conquistar a su amada. En contrapartida a todos estos personajes que adoran estar en un escenario, en Mi amigo pintor se presenta a un niño que no quería ser actor, él solo quería pintar, pero paradójicamente es en un escenario donde descubre su vocación. Podría decirse que en la obra de Lygia Bojunga la representación teatral aparece como un medio

\footnotetext{
${ }^{16}$ En la obra de Lygia Bojunga, a través de la relaciones de Angélica y Puerto, La mujer barbuda y Fueguito o la Familia de la casa de los arreglos, se muestra al lector un modelo de relación amorosa e igualitaria, en contraste con aquellas relaciones donde predomina un tratamiento opresor, sin embargo, tal como plantea Eliana Yunes, "la autora narra con su mirada y deja la formulación crítica por cuenta del lector. (YUNES, 1996, p. 2)

${ }^{17}$ Esta tendencia podría corresponderse con el oficio de Lygia Bojunga, quien como es sabido también es dramaturga.
} 
en el cual los personajes pueden poner en escena eso que son, o lo que no son, practicar, equivocarse y aceptar, encontrar las respuestas y descubrir verdades en el proceso.

Se verá, que si tal como ha señalado Antonio Cándido, la literatura funciona "desenvolviendo en nosotros una cuota de humanidad, en la medida en que nos torna comprensivos y abiertos para la naturaleza, la sociedad y nuestros semejantes" (CÁNDIDO, 2014, p.180) en la obra de Lygia Bojunga tanto el acto de escribir como el de representar teatralmente, aparecerán como medios para que los personajes se acerquen más a ser sujetos, pudiéndose confirmar el argumento de que la literatura humaniza porque hace vivir y en ese sentido tanto del acto de escribir como el de la representación teatral, considerando su carácter literario, permitirán a los personajes vivir, tener acceso a otras experiencias y a otros mundos posibles.

Se verá que en la narrativa de Lygia Bojunga se hace tangible un proyecto humanizador, que buscar hacer que la infancia sea considerada en cuanto sujeto dentro de la sociedad, poniendo en funcionamiento una característica inherente al arte, la denuncia, pues como bien lo ha señalado Laura Sandroni, "el arte al mismo tiempo que es encantamiento, magia, es también denunciadora" (SANDRONI, 2013, s/p). Así, el proyecto narrativo de Lygia Bojunga servirá para poner en escena y representar las historias de estos personajes, que pese a pertenecer al plano de la ficción se parecen bastante a la realidad.

\section{Episodios de la subalternización.}

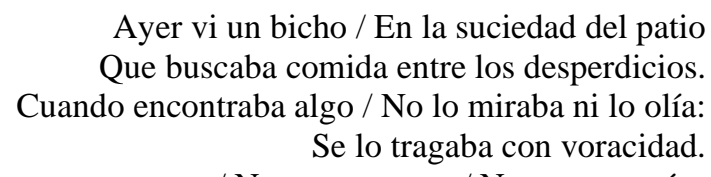

Ayer vi un bicho / En la suciedad del patio Que buscaba comida entre los desperdicios. Se lo tragaba con voracidad. El bicho no era un gato / No era un perro / No era un ratón. El bicho, Dios mío, era un hombre.

El Bicho - Manuel Bandeira

Este duro poema de Manuel Bandeira permite establecer un vínculo con el argumento de la obra Los amigos (1972); estos animales antropomorfizados, en el sentido en que viven, piensan y sufren tanto o más que un humano, son muy diferentes el uno del otro, pero tienen algo en común, están "cansados de ese negocio de huir, de tener que arriesgar la vida todo el día, de tener que vivir sin saber si van a conseguir comida o no". Por ello, para sobrevivir necesitan encontrar una forma de sustento, y esta será el arte.

- ¿Y si salimos de payasos? 
Fue solo él hablar de payasos que todos se acordaron del circo, de los payasos que habían visto en la carpa haciendo tantas gracias que todo el mundo moría de risa. Gritaron juntos sin pensar en más nada.

- ¡Genial! (Bojunga, 1972, p.33)

Sin embargo, para llevar a cabo este plan los amigos tendrán que buscar en la basura, no tienen otra opción, y aunque participan festivos en el carnaval: "sábado, domingo, lunes, martes el bloque de los amigos andaba en las calles, se mezclaba con los otros fiesteros, con las escuelas de samba" (1972: 41), y durante esos días el grupo se sintió parte de la sociedad, casi como si no hubiese diferencias entre ellos y el resto de los ciudadanos, todos saben que el carnaval tiene su final, y tan pronto llegó el miércoles, ya exhaustos, se encontraron durmiendo de nuevo en la calle y lo peor de todo, ahora llegaba la perrera para llevárselos. Como esta escena existen muchos otros episodios dolorosos en la obra, a partir de los cuáles el lector puede reflexionar e inclusive preguntarse si la autora efectivamente está hablando de la historia de unos "cachorros vira latas".

En la novela La casa de la Madrina (1978) su protagonista, Alexandre, es un niño pobre que vive en una favela. Aunque Augusto, su hermano mayor le cuenta historias maravillosas para despertar su esperanza, sus sueños e imaginación, y hace todo lo posible para que Alexander pueda estudiar, en algún momento se presentarán dificultades que harán que Alexandre ya no pueda ir a la escuela y deba volver a trabajar para ayudar a sostener a su familia. "La madre, la novia, la hermana, todo mundo dijo que era por poco tiempo que Alexander iba a parar de estudiar" (1978, p. 32), sin embargo esta situación se extendió y Alexandre tuvo que volver a la playa, a la vida de quien tiene que ganarse el pan de cada día, y esta experiencia el lector puede sentirla de primera mano a través del discurso del niño:

\footnotetext{
Y sabes cómo es, ¿no? caminando sobre la arena, con ese calor horrible, tenemos que cargar mucho hielo en la caja para que el helado esté siempre frío. Un peso que te diré. Pero ahora hay tanta gente vendiendo helados que camino cinco, seis veces por toda la playa y sin vender casi nada (BOJUNGA, 1978, p. 11)
}

La situación en la playa era difícil, entonces Alexandre intenta otro trabajo que un conocido le comenta, el de conseguir taxis para clientes, sin embargo el día en que se dispone a empezar en ese nuevo empleo se da cuenta que "ya había cuatro chicos "trabajando" en aquel mismo punto". Alexander "tenía que escapar de ser atropellado, tenía que escapar de ser empujado, tenía que escapar de tanta cosa” (1978: 42), que de nuevo el lector experimenta de cerca la odisea que significa para este niño tener que trabajar; entonces el lector percibe que ya no se trata sólo del mundo de la ficción, sino que la autora también está hablando de la realidad de muchos otros niños en el mundo real. 
Cuando Alexandre todavía iba a la escuela, en una ocasión le correspondió compartir con sus compañeros su día a día, “contar su vida, mostrar lo que él sabía hacer”, entonces contó para todos como él se ganaba la vida vendiendo cosas en la playa. Unos de los padres de los otros niños escuchó el discurso de Alexandre y preguntó para la maestra: “¿Usted está queriendo enseñar a mi hijo a ganarse la vida vendiendo maní?” (BOJUNGA, 1978, p.29). En esta última línea puede verse cómo la sociedad reprueba que ciertos niños tengan que trabajar, pero realmente no le afecta que muchos otros niños se vean obligados a hacerlo. En el libro se observa la indolencia y la hipocresía de la sociedad, y también se devela la dura verdad tras el trabajo infantil. Cuando Alexandre se cansa de ese día a día en la cual se encuentra inmerso decide ir tras sus sueños, emprendiendo camino hacia la casa de su madrina, un lugar donde él podría ser feliz, y nunca le faltaría nada.

Para Alexandre ir a la casa de la madrina significa tener una nueva vida, libre de carencias, sin hambre, tener un espacio, una habitación propia, alejarse de su cruel realidad; por eso no duda ni un minuto sobre la existencia de su madrina, se aferra a esta idea, e inclusive cuando le plantean la posibilidad de que esta no sea real, él dice lo siguiente: "Ya me habían avisado que los adultos tiene envidia de la madrina de los niños... Es sólo llegar la envidia que ellos empiezan a querer hacer desaparecer nuestra madrina” (BOJUNGA, 1978, p. 63).

Pareciese estarse hablando de forma metafórica sobre los sueños y las ilusiones de los niños, y de que los adultos adoran acabar con la inocencia, con la esperanza. Para Alexandre la casa de la madrina es una utopía a la que él se aferra, y aunque sólo puede llegar a ella a través de la imaginación, esa visión que quedó en su memoria le servirá como refugio cada vez que la necesite. La casa de la madrina representa la utopía, y como ha dicho Eduardo Galeno, "para eso sirve la utopía, para caminar".

Sobre los sueños, las metas y las ideas, sería interesante reflexionar cómo en la novela Angélica (1975) se habla sobre la importancia de que cada quien desarrolle su propio criterio; para ello se muestra al lector el episodio de los sapitos González, en especial se menciona a Rabanete, quien "creía que creer era muy difícil: pensaba, pensaba y acababa siempre diciendo: "No lo sé” (BOJUNGA, 1975, p.127), porque quizás tenía miedo, era inseguro o tímido, el caso es que nunca se atrevía a expresar sus ideas. Pero una vez que Angélica y Puerto invitaron a los sapitos González a participar en su obra de teatro, y conforme fueron pasando los días, entre ensayo y ensayo, Rabanete se fue sintiendo más y más cómodo, hasta que justo un día dijo: “¡Creo algo!”, y “Todo el mundo aplaudió: era la primera vez que Rabanete creía”. 
En este simple diálogo se condensa un planteamiento crucial en esta novela, el derecho a expresarse-. Se presenta al lector una paradoja, mientras Rabanete tiene derecho a hablar pero no lo usa, la "Mujer de Jota" es impedida por su marido, un personaje machista que piensa que las mujeres no deben hablar, no deben trabajar, no deben actuar; pero es precisamente a través de la representación teatral donde la mujer de Jota encontrará espacio para expresar su propia voz y decir:

- Un momentico, Jota. Sólo un momentico. Déjame terminar lo que estaba diciendo. Es lo siguiente: quería decirles que yo tengo nombre. Un nombre que también comienza por jota. ¿Qué coincidencia!, ¿no? Pues sí: me llamo Jacinta. Y quería pedirles a todos los presentes que no me llamen más Mujer de Jota. De aquí en adelante, todo el mundo me llamará Jacinta, ¿bien? — suspiró, aliviada y satisfecha— . Listo, era sólo eso - y se sentó.

Como puede observarse, no sólo Angélica, Jacinta o Rabanete consiguen en el teatro un lugar para expresarse, para que se escuche su voz, sino que también los otros personajes en la obra de Lygia Bojunga a través de la representación consiguen alcanzar la libertad, la independencia, la realización laboral, seguir su vocación, permitiendo con esto señalar que en el universo de la narrativa bojunguiana el lenguaje narrativo se articula con el lenguaje teatral, para que a partir de un discurso metaliterario, los personajes puedan expresarse con sus propias palabras, permitiendo al lector trasladarse o acercarse al lugar de habla de cada uno de ellos.

\section{La voz de la infancia en peligro}

No podemos terminar este trabajo sin mencionar El Bolso Amarillo (1976) novela donde se narra el mundo a partir de modo de visión de Raquel, una niña que tiene tres deseos: el de ser niño, el de ser adulto y el de ser escritora. Ella se encuentra inmersa en una familia donde su nacimiento no fue deseado, donde no la comprenden, no la escuchan, no la respetan, e inclusive ríen de ella; la niña resuelve empezar a escribir como una forma de vencer la soledad y reflexionar sobre sus problemas. Un día Raquel recibe como regalo un bolso amarillo, y éste, metáfora de su inconsciente, servirá como un espacio donde Raquel puede depositar y desarrollar todos sus deseos.

Sin embargo esta novela que sería galardonada en 1978 con el Premio Lo Mejor para el Joven por la FNLIJ ${ }^{18}$, justo en el año 2019 ha sido objeto de censura ${ }^{19}$. Este acontecimiento ha sido citado por la doctora Ana Crelia Dias, especialista en literatura infantil y juvenil, para

\footnotetext{
${ }^{18}$ Fundación Nacional del Libro Infantil y Juvenil , Brasil.

${ }^{19}$ El vereador de una ciudad del interior de São Paulo acusó a esta de contener ideología de género, manifestando su rechazo ante la adopción de la obra por la red municipal de educación (Dias, 2019)
} 
explicar que si bien durante la "década de 1970 del siglo 20 la censura se mantuvo distante de ese tipo de obras que allí se producían, no se puede decir lo mismo en relación a los tiempos actuales", denunciado que estos acontecimientos evidencian "un escenario en que el conservadurismo instala sus redes como tuteladores de la infancia” (Dias, 2019), ejerciéndose así una actividad que deja ver la verdadera intención del sistema educativo actual.

A partir de este hecho podría deducirse que quizás el error resida en que cualquiera se cree capaz de opinar sobre la educación de la infancia, pero es importante entender que la realidad no se construye con "buenas intenciones". Si acaso es cierta la consigna de que "los niños y jóvenes son el futuro del mundo" será necesario que la familia, la escuela y la sociedad dejen se proyectar sus expectativas en la infancia y comiencen a preocuparse verdaderamente por el bienestar de todos ellos, y no por lo que pueden o no pueden leer.

\section{Consideraciones finales}

Si en la narrativa bojunguiana se representa a la infancia en una "relación conflictiva con la familia" 20 o con el mundo de los adultos, es porque el proyecto de la autora se preocupa por denunciar las situaciones donde la infancia se encuentra en una situación de subalternidad; y esto lo hace al hablar de niños y jóvenes cuya voz no es tomada en cuenta, al visibilizar circunstancias donde la creatividad de la infancia es apagada, y también cuando se muestra la realidad de niños pobres, de niños huérfanos, de niños en situación de abuso o testigos de la violencia, ofreciendo de este modo un acercamiento a este lugar de habla y por ende a la posibilidad de que tener acceso a estos acontecimientos, permitiendo al lector realizar sus propios posicionamientos críticos.

Creemos que es allí donde reside la necesidad de la literatura infantil y juvenil, pues aunque todo esto sea dicho en el ámbito de la ficción, este quizás sea uno de los pocos espacios donde la infancia puede verse representada y encontrar allí historias similares a la suya, o totalmente diferentes; de cualquier forma, como ha señalado Michelle Petit, los libros pasarán a ser esas "moradas emprestadas donde es posible sentirse protegido y soñar con otros futuros, elaborar una distancia, mudar de punto de vista" (2009, p. 212).

No en vano la propia Lygia Bojunga en Libro, un encuentro manifestará que para ella desde muy pequeña los libros fueron casa y comida; quizás haya sido esta experiencia la que llevaría a la autora a desarrollar un proyecto narrativo en el cual se presenta a la literatura como

${ }^{20}$ (ZILBERMAN, 2003, p. 219) 
una forma de materializar los sueños; así la autora hará uso de un discurso metaliterario, implementando herramientas como la escritura o el teatro para sumergir al lector en su universo, de modo que reflexionando sobre la forma, la elaboración e intencionalidad de sus textos, la autora permite al lector un primer acceso al mundo de la literatura y de este modo hacerse participe del proceso de creación literaria.

Por último quisiéramos destacar un planteamiento de Silvia Castrillón cuando señala que "la lectura no es buena ni mala en sí misma. Tener acceso a la lectura no garante de manera absoluta la democracia, pero no tenerlo definitivamente lo impide o por lo menos lo retarda. (CASTRILLÓN, 2011, p. 3). Se hará necesario recalcar que si obras como la de Lygia Bojunga que propician la autonomía del pensamiento, son censuradas, criticadas, o acusadas de adoctrinamiento ideológico, esto se debe a que las ideas allí expresadas se encuentran en conflicto con el enfoque de la educación actual, de la sociedad en general; pero es precisamente para luchar contra esta realidad que es necesario sumar esfuerzos y desarrollar iniciativas que permitan garantizar el acceso a los libros por parte de los niños y jóvenes del mundo entero, para que este modo la lectura deje de ser un privilegio y se convierta finalmente en un derecho.

\section{Referências}

ANDUETTO, María Teresa. Hacia una literatura sin adjetivos. Sao Paulo. Editora Pulo de Gato. 2009.

BOJUNGA, Lygia. Los amigos. Rio de Janeiro. Casa Lygia Bojunga. 1972

BOJUNGA, Lygia. Angélica. Colombia. Editorial Norma. 1975.

BOJUNGA, Lygia. La bolsa amarilla. Rio de Janeiro. Casa Lygia Bojunga. 1976

BOJUNGA, Lygia. La casa de ma madrina. Rio de Janeiro. Casa Lygia Bojunga. 1978

BOJUNGA, Lygia. La cuerda floja. Rio de Janeiro. Casa Lygia Bojunga. 1979

BOJUNGA, Lygia. El sofá estampado. Rio de Janeiro. Casa Lygia Bojunga. 1980

BOJUNGA, Lygia. Adiós. Rio de Janeiro. Casa Lygia Bojunga. 1984

BOJUNGA, Lygia. Nosotros tres. Agir Editora. Rio de Janeiro. 1987.

BOJUNGA, Lygia. Mi amigo Pintor. México. Editorial Alfaguara. 1992

BOJUNGA, Lygia. Libro, un encuentro. Rio de Janeiro. Casa Lygia Bojunga. 1988.

CÁNDIDO, Antonio. "El derecho a la literatura", en Varios escritos. Dos ciudades. Rio de Janeiro. Editorial Oro sobre Azul. 2014. 
CASTRILLÓN, Silvia. O direito de ler e de escrever. São Pailo. Editora Pulo de Gato. 2011

DIAS, Ana Crélia. Territorios en conficto. Curitiba. Jornal Rascunho. 2019 Disponible en: http://rascunho.com.br/territorios-em-conflito/

FIGUEROA Grenett, Claudio. Infancia y ciudadanía: producción de subjetividad en el caso del movimiento por una cultura de derechos de niñez y adolescencia. Disponible en: http://repositorio.uchile.cl/bitstream/handle/2250/145756/Infancia\%20y\%20ciudadan\%C3\%A Da.pdf?sequence $=1 \&$ isAllowed $=\mathrm{y}$

FREIRE, Paulo. La Acción Cultural para la Libertad y otros Escritos. Traducción Claudia Schilling. Buenos Aires: Tierra Nueva. 1975

SANDRONI, Laura. De Lobato a Bojunga - as reinações renovadas. Nova Fronteira. eBook Kindle. 2013.

SILVA, Luiza Helena Oliveira de; MELO, Márcio Araújo de. Que pode o leitor? ENTRELETRAS, Araguaína/TO, v. 6, n. 2, jul/dez. 2015 (ISSN 2179-394-online) disponível em: https://sistemas.uft.edu.br/periodicos/index.php/entreletras/article/view/2736/8943

SPIVAC, Gayitri. ¿Puede hablar el subalterno? Bogotá, Colombia. Revista Colombiana de Antropología, vol. 39, enero-diciembre, 2003, pp. 297-364

TIETZMANN Silva, Vera María. La ambivalencia del mar en Lygia Bojunga Nunes. Revista Latinoamericana de Literatura Infantil y Juvenil 1, enero-junio 1995, pp. 35-42.

YUNES, Eliana. Lygia Bojunga ou uma literatura em processo. Proleitura. Assis: UNESP, v.9 - fev. 1996

ZILBERMAN, Regina; LAJOLO, Marisa. Literatura infantil brasileira: história e histórias. São Paulo: Ática, 1985.

ZILBERMAN, Regina. La literatura infantil en la escuela. São Paulo; Global Editora. 2003.

Recebido em 20 de setembro de 2019 Aceito em 14 de novembro de 2019 